\title{
Identification Of The Social Development In Early Childhood In Pakistan
}

Asif Malik, University of Sargodha, Pakistan

Muhammad Sarwar, University of Sargodha, Pakistan

Naeemullah Khan, Punjab Education Department, Pakistan

\begin{abstract}
This study was conducted to identify the social development in early childhood years. It was delimited to eight private schools of Lahore City from the area of Faisal Town and Shadman. Forty students (male and female) were randomly selected as the sample. Five students from Nursery, Prep and grade one were selected from each school. A checklist was developed by reviewing the related literature which covered attributes of social developments under the sections of individual, social skills, peer relationships and communication skills. It was revealed that individual, social skills, peer relationships and communication skills were developed in the children but a positive mood was lacking in them at this stage.
\end{abstract}

Keywords: Social development, early childhood, teachers, parents, Pakistan

\section{INTRODUCTION}

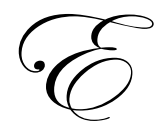

arly childhood is a time of tremendous growth and development for children in every way - physical, social, emotional, and intellectual (Child Trends and Center for Child Health Research, 2004). All aspects of adult human capital, from work force skills to cooperative and lawful behaviour, build on capacities that are developed during childhood beginning at birth (The Science of Early Childhood Development, 2007). Gordon and Brown (2000) have defined early childhood education as pre-school, Kindergarten, Nursery, Montessori and primary education from 3 to 8 years. The preschools, nursery and play groups can provide a valuable base by provision of systematic and guided play for later social development (Erwin and Letchford, 2003).

In Pakistan, early childhood education is getting more and more momentum. A decade ago, early childhood education was considered a luxury in such a country where provision of primary education for the population of all school ages was still a dream. Now the situation is improving and universities in Pakistan are offering courses in early childhood education. Parents are becoming increasingly aware of the significance of early childhood education for the development of the child. The Higher Education Commission of Pakistan is arranging training workshops for teacher trainers.

\section{Development in Early Childhood}

Successful personal, social and moral development is critical for every young child in all aspects of their lives and gives them the best opportunity for success in all other areas of learning (Martin, 2005). The development of good cognitive skills, emotional well-being, and social competence in early childhood forms a strong foundation of success in adulthood (The Science of Early Childhood Development, 2007).

Development is a change that results from a movement toward a goal. In psychological sense, it refers to certain changes that occur in human beings between conception and death. Development is a process which brings qualitative changes in a person, including changes in physical, cognitive and social aspects. Physical development includes the refinement of motor behaviour and physiological aspect changes, such as puberty and aging. Cardwell and Flanagan (2005) state that cognitive development is one of those terms in psychology that covers a wide range of behaviours, such as development of memory, intelligence, reasoning, problem-solving, and so on. It is, therefore, 
generally used to refer to the changes in a person's cognitive (mental) structures which occur during a person's life span. Socialization, according to Donnel (2002), is the process of learning by which people of all ages acquire the culture of their society and of the various groups to which they belong.

\section{Theories of Development}

Different psychologists have interpreted the process of development. In all theories, developing abilities are built "from the bottom up" with simple skills providing a base for more advanced skills over time (The Science of Early Childhood Development, 2007).

Learning is a reciprocal experience for the students and teacher (Vygotsky, 1978). Vygotsky believed that it is very important for teachers to identify what a child can do, what he knows already, and then build on this existing knowledge to help the child make sense of the world (Drury, Miller and Cambell, 2000). In his theory, social interaction plays a fundamental role in the process of cognitive development (Vygotsky, 1978).

Erikson's psychosocial theory of development considers the impact of external factors, parents, and society on personality development from childhood to adulthood (Erikson, 1968).

Jean Piaget's stages of cognitive development describe the intellectual development of children from infancy to early adulthood. Piaget believed that children are not less intelligent than adults; they simply think differently (Piaget's Stages of Cognitive Development, 2009).

\section{Social Interaction and Social Development}

Hartup (1992) suggests that peer relationships contribute a great deal to both social and cognitive development and to the effectiveness with which we function as adults. Social skills are strategies children learn that enable them to behave appropriately in different situations. They help children learn to initiate or manage social interaction in a variety of settings and with a number of people. In an early childhood setting, children learn a great deal about social behavior and expectations. They develop many skills as they learn to interact with adults other than their parents and siblings.

Behaviour is produced, or at least influenced, heavily by some contextual or situational factors (Li-Jun Ji, Kaiping Peng, Richard E. Nisbett, 2000). Understanding about oneself and others is dependent on social and emotional interactions in which cognitive processes come into play (Maynard and Thomas, 2004). The children who have the ability to get along with others in a constructive manner are socially competent (Child Trends and Center for Child Health Research, 2004). Quality of parent child relationships influences children's future relationships (Dunn, 1995). Providing a child with necessary assistance at the preschool level, rather than assuming they will grow out of behaviour problems, can give the child a better opportunity to establish new friendships and positive reputations as they progress through school (Christine Johnson, Marsha Ironsmith, Charles W. Snow1, and G. Michael Poteat, 2000).

\section{Family and Social Development}

There is an important link between parental opportunities provided for play and the peer social system (Bullock, 1989). Initial social relationships are developed in a family and are most important in shaping children's early behaviour and thinking because children model their behaviour and attitudes on family members (Jordan, Carlile and Stack, 2008). Tamis-LeMonda, Way and Hughes (2008) stated that Parents transmit values, rules, and standards about ways of thinking and acting, and provide an interpretive lens through which children view social relationships and structures. Social skills emerge as children learn to function as members of a group and as they come to understand themselves as social beings.

Children differ in their relationships with their parents (Dunn, 1995). Mother mostly takes care of the child, and her impact on the personality of the child cannot be overemphasized. The role of father is also being acknowledged. Children raised with responsible fathers tend to get along better with their peers, are academically 
successful, stay in school longer, and use drugs and alcohol less frequently. Active fathers have children who score higher on tests of verbal skills, in problem-solving tasks, and in social situations (Ladd, 2000).

\section{Peer Group and Social Development}

Peer relationships are thought to play an important role in children's development and offer unique opportunities for getting acquainted with the social norms and processes involved in interpersonal relationships, and for learning new social skills.

Children learn social skills by interacting with their classmates and adults (Jordan, Carlile and Stack, 2008). Learning occurs within social contexts which inform, develop, deepen and influence an individual's identity, thinking, learning and meaning-making process (Jordan, Carlile and Stack, 2008). In a peer group, individuals learn to interact, behave and conform in social acceptable ways. They acquire social roles, responsibilities and identities which are developed through relationships and group participation (Jordan, Carlile and Stack, 2008). In friendship, children attempt to conciliate, negotiate, make compromises with more success, and develop more cognitive abilities (Dunn , 2004).

Peer relationships in childhood are a major predictor of psychological adjustment in adulthood (Christine et al, 2000). Preschool seems to be a critical period for children's social development and one that teachers and parents cannot afford to ignore (ibid).

\section{Teachers' Contributions in Social Development}

Preschool teachers sometimes find that parents push for academic readiness skills to be taught to their children at the preschool level. Research suggests that it may be more important for preschool teachers to spend time encouraging the development of social skills (Christine Johnson, Marsha Ironsmith, Charles W. Snow1, and G. Michael Poteat, 2000).

Therefore, it is important for teachers and parents to help very young children develop positive social skills and friendships as these may have a strong impact on peer acceptance (Christine, Ironsmith, Charles, and Poteat, 2000). The teacher should consider the level of stress the kids feel in school. Stress in early childhood can be either growth promoting or seriously damaging.

Toxic stress in early childhood is associated with persistent effects on the nervous system and stress hormone systems that can lead to lifelong problems in learning, behaviour and both physical and mental health. A second type of stress facilitates coping with difficult situations and restores stress hormones to baseline.

\section{Attributes of Social Development}

This article covered the areas of social development, such as individual, social skill, peer relationship and communication skills attributes. The individual attributes include: mood, relationship with peers, and thanking for help at the age of 3-4 years. Expressing interest in small group activities, willingly coming to school and positive mood in school activities are individual attributes at the age of 4-6 years. Similarly, displaying a sense of humour, loneliness, and verbalization of emotions to solve conflicts are individual attributes supposedly possessed at the age of 6-8 years.

Social attributes have been given in three age brackets (3-4 years, 4-6 years, and 6-8 years). Interacting non-verbally, taking part in games, exchanging information with others, and participation in group activities are social attributes at the age of 3-4years. Drawing appropriate attention to self, attending to short stories, and interacting in a socially approved way with adults are social attributes at the age of 4-6 years. Similarly, responding verbally to social small tasks imitated by adults, exhibiting a positive interaction in a group setting, organizing a group to participate in games/activities, and using others in a group to facilitate problem-solving in a conflict situation are social attributes at the age of 6-8 years. 
The peer relationship attributes have been given in three age brackets (3-4 years, 4-6 years, and 6-8 years). For ages 3-4 years, the children are supposed to follow peers' requests, play with peers with a minimal amount of conflict, and feel embarrassed if his words or habits are told to someone. For ages 4-6 years, the children are supposed to initiate a friendly relationship with peers, greet familiar adults/peers without a reminder, help peers with simple tasks, and participate in cooperative play with a small group of children. Similarly, 6-8 year-old students are supposed to show a preference for some friends over others, sensitive to other children/peers and show clear attachment to peers.

The communication skills attributes have been given in three age brackets (3-4 years, 4-6 years, and 6-8 years). For ages 3-4 years, the children are supposed to imitate babbling sounds and/or familiar words, understand simple questions, show positive response to talk, and pick up words of older people. For ages 4-6 years, the children are supposed to tell a simple experience, describe items and/or actions in books, believe one part of a verbal message, and hesitate to answer the questions of others. Similarly, 6-8 year-old students are supposed to name at least eight animals, show an interest in novel words, and prefer to complete everything themselves.

Keeping in view the importance of social development at an early childhood level and scarcity of research at this level in Pakistan, an empirical study of social development is the need of the hour. This study may be useful for teachers, parents and policy makers for facilitating the social development of children at an early age.

Key questions of the study were:

1. To what extent are individual attributes of children developed from the age of 3-8 years?

2. To what extent are social skills attributes of children developed from the age of 3-8 years?

3. To what extent are peer relationship attributes of children developed from the age of 3-8 years?

4. To what extent are communication skills attributes of children developed from the age of 3-8 years?

\section{METHODOLOGY}

\section{Design}

The present study was descriptive in nature. It identified the social development in early childhood, such as individual attributes, social skills attributes, peer relationship attributes and communication skills attributes.

\section{Subjects}

One hundred and twenty students (male and female) from eight privately managed primary schools of Lahore city (Shadman and Faisal Town) were selected randomly as the sample. All students of the ages 3-8 were identified and divided into three strata (3-4 years, 4-6 years and 6-8 years). Five students were randomly selected from each stratum; in this way, 15 students were selected from each school.

\section{Instrument}

A checklist was prepared in the light of available literature. It contained three parts (3-4 years, 4-6 years and 6-8 years). Further, each part had four sections of related items, such as individual attributes, social skills attributes, peer relationship attributes, and communication skills attributes. A checklist helped collect the data about children's social development.

\section{Procedure}

A checklist was developed and validated by three experts of early childhood education and it consisted of 53 items to measure "the social development in early learners". Two columns of 'yes' and 'no' were shown against each item seeking the opinion of teachers. This checklist covered the areas of development, such as individual attributes, social skills attributes, peer relationship attributes and communication skills attributes. One of the researchers personally visited all the schools, distributed the checklist among the teachers of privately managed 
primary schools in Shadman and Faisal Town, and briefed them in how to observe the students and record the observations. Each teacher filled out a separate observational sheet for every child selected in the class. After one week, the researcher collected all observational sheets from the teachers.

\section{Data Analysis}

To reach certain conclusions, percentages were computed to identify various patterns in the data.

\section{RESULTS}

Table 1: Items Relating to Individual Attributes

\begin{tabular}{|c|l|c|c|}
\hline \multicolumn{1}{|c|}{ Ages 3-4 Years } & Yes \% & No \% \\
\hline S.\# & \multicolumn{1}{|c|}{ Items } & 40 & 60 \\
\hline 1 & Child is usually in a positive mood in school & 75 & 25 \\
\hline 2 & Has a positive relationship with one or two peers & 30 & 70 \\
\hline 3 & Says "please" or "thank you" when reminded & & \\
\hline & Ages 4-6 years & 75 & 25 \\
\hline 4 & Expresses his/her interest in small group activities & 60 & 40 \\
\hline 5 & Child usually comes to school willingly & 98 & 2 \\
\hline 6 & Shows a positive mood in school activities & & \\
\hline & Ages 6-8 years & 78 & 22 \\
\hline 7 & Displays a sense of humour & 68 & 32 \\
\hline 8 & Does not seem to be acutely alone & 85 & 15 \\
\hline 9 & Verbalizes emotions to resolve conflict with peers & & 2 \\
\hline
\end{tabular}

Table 1 indicates that $60 \%$ of children age 3-4 do not usually show a positive mood during the entire day. However, $75 \%$ have a positive relationship with peers and only $30 \%$ of children of the same age group say "thank you" when reminded.

The table further shows that $98 \%$ of children ages 4-6 show a positive mood in school activities. Sixty percent of children attend school willingly, whereas $75 \%$ express their interest in small group activities.

Table 1 also indicates that $85 \%$ of children ages 6-8 verbalize their emotions to resolve conflicts with peers and $32 \%$ seem to be acutely alone. A sense of humour was displayed by $78 \%$ of children.

Table 2: Items Relating to Social Skills Attributes

\begin{tabular}{|c|l|c|c|}
\hline \multicolumn{1}{|c|}{ Ages 3-4 Years } & Yes \% & No \% \\
\hline S.\# & \multicolumn{1}{|c|}{ Items } & 65 & 35 \\
\hline 1 & Interacts non-verbally with other children with smiles, waves, nods, etc. & 65 & 35 \\
\hline 2 & Takes part in games, such as pushing a car or rolling a ball with adults & 60 & 40 \\
\hline 3 & Interacts and exchanges information with others & 68 & \\
\hline 4 & Participates in group activities in the classroom & 60 & \\
\hline & Ages 4-6 years & 88 & 40 \\
\hline 5 & Draws appropriate attention to self & 88 & 12 \\
\hline 6 & Attends to short stories for 5-10 minutes & & \\
\hline 7 & Interacts in a socially approved way with adults & 90 & \\
\hline & Ages 6-8 years & 65 & \\
\hline 7 & Responds verbally to social small tasks imitated by adults & 70 & 35 \\
\hline 8 & Exhibits positive interaction in a group setting & 65 & 30 \\
\hline 9 & Organizes a group to participate in games/activities & 35 \\
\hline 10 & Uses others in the group to facilitate problem-solving in a conflict situation & & 35 \\
\hline
\end{tabular}


Table 2 indicates that $65 \%$ of children ages 3-4 interact non-verbally with other children with smiles, waves, nods, etc. and take part in games, such as pushing a car and rolling a ball with adults. Interaction and exchange of information with others was displayed by $60 \%$ of children, and $68 \%$ participate in group activities in the classroom.

The table further indicates that $88 \%$ of children ages 4-6 can attend short stories for 5-10 minutes and interact in a socially approved way with adults. Inappropriate attention to self was drawn by $40 \%$ of children.

Table 2 also shows that $90 \%$ of children ages 6-8 respond verbally to small social tasks initiated by adults. Sixty-five percent exhibit a positive interaction in a group setting, and the same percentage responded that they use others in the group to facilitate problem-solving in a conflict situation.

Table 3: Items Relating to Peer Relationship Attributes

\begin{tabular}{|c|l|c|c|}
\hline \multicolumn{1}{|c|}{ Ages 3-4 Years } & \multicolumn{1}{|c|}{ Yes \% } & No \% \\
\hline S.\# & \multicolumn{1}{|c|}{ Items } & 60 & 40 \\
\hline 1 & Generally follows peers' directions, requests, etc. & 63 & 37 \\
\hline 2 & Plays with peers with minimal amount of conflict & 75 & 25 \\
\hline 3 & Feels embarrassed if his words or habits are told to someone & 80 & 20 \\
\hline & Ages 4-6 years & 70 & 30 \\
\hline 4 & Child initiates friendly relationship with peers & 83 & 17 \\
\hline 5 & Greets familiar adults/peers without a reminder & 100 & 0 \\
\hline 6 & Helps peers with simple tasks & & \\
\hline 7 & Frequently participates in cooperative play with a small group of children & 85 & 15 \\
\hline & Ages 6-8 years & 83 & 17 \\
\hline 9 & Shows a preference for some friends over others & 95 & 5 \\
\hline 10 & Child is usually sensitive to other children/peers & Shows clear attachment to peers & 5 \\
\hline
\end{tabular}

Table 3 indicates that $75 \%$ of children ages 3-4 feel embarrassed when their words or habits are told to someone. A minimal amount of conflict, while playing with peers, was shown by $63 \%$ of children, whereas $30 \%$ do not follow peers' directions, requests, etc.

The table further shows that $100 \%$ of children ages 4-6 participate in cooperative play with a small group of children. Eighty-three percent help peers with simple tasks and $80 \%$ of children initiate a friendly relationship with peers. Familiar adults/peers are not greeted without a reminder by $30 \%$ of children.

Table 3 also shows that preference for some friends over others is shown by $85 \%$ of children ages $6-8$. Only $5 \%$ do not show an attachment to peers, whereas $83 \%$ of children display sensitivity to other children/peers.

Table 4: Items Relating to Communication Skills Attributes

\begin{tabular}{|c|l|c|c|}
\hline \multicolumn{1}{|c|}{ Ages 3-4 Years } & Yes \% & No \% \\
\hline S.\# & \multicolumn{1}{|c|}{ Items } & 73 & 27 \\
\hline 1 & Imitates babbling sounds and/or familiar words & 75 & 25 \\
\hline 2 & Understands simple questions & 65 & 35 \\
\hline 3 & Shows positive response to talk & 75 & 25 \\
\hline 4 & Picks up words of older people & 85 & \\
\hline & Ages 4-6 years & 63 & 15 \\
\hline 5 & Child tells a simple experience & 80 & 37 \\
\hline 6 & Describes items and/or actions in books & 60 & 20 \\
\hline 7 & Delivers one part of verbal message & & 40 \\
\hline 8 & Hesitates to answer the questions of others & 98 & \\
\hline & Ages 6-8 years & 20 & 8 \\
\hline 10 & Names at least eight animals & 83 & \\
\hline 11 & Shows an interest in novel words & 20 \\
\hline
\end{tabular}


Table 4 indicates that imitation of babbling sounds and/or familiar words is made by $73 \%$ of children ages 3-4 and 75\% understand simple questions and pick up words of older people. Sixty-five percent of children show positive response to talk.

The table further shows that $85 \%$ of children ages 4-6 are able to tell a simple experience and $80 \%$ are able to deliver one part of a verbal message. Hesitation was displayed by $40 \%$ of children to answer the questions of others and $63 \%$ described items and/or actions in books.

Table 4 also shows that $98 \%$ of children ages 6-8 are able to name at least eight animals and interest in novel words is shown by only $20 \%$. Eighty-three percent of children like to complete everything by themselves.

\section{RESULTS AND DISCUSSIONS}

The majority of children ages 3-4 do not, usually in a positive mood, say "please" or "thank you", even when reminded; but they have a positive relationship with their peers. However, the majority of children ages 4-6 show interest in group activities, usually come to school willingly, and participate in school activities. Similarly, the majority of children ages 6-8 display a sense of humour, verbalize emotions to resolve conflicts with their peers and have a friendship with them. The results show that the majority of children ages 3-8 reflect the characteristics of individual attributes, except the characteristics of a positive mood and ability to say please or thank you at ages 3-4. The children may develop a negative mood due to poor training of the parents. Initial social relationships are developed in a family and are most important in shaping children's early behaviour and thinking because children model their behaviour and attitudes of family members (Jordan, Carlile and Stack, 2008). Parents transmit values, rules, and standards about ways of thinking and acting and provide an interpretive lens through which children view social relationships and structures (Tamis-LeMonda, Way and Hughes, 2008). Saying please or thank you is a social skill and emerges when children learn to function as members of a group and as they come to understand themselves as social beings.

The majority of children ages 3-4 interact with other children with smiles, participate in group activities, exchange information with each other, and take part in games. Moreover, the majority of children ages 4-6 draw attention to themselves and interact with adults in a socially acceptable way. Similarly, the majority of children ages 6-8 imitate adults, interact in groups, participate in games, and take help from their peers in problem-solving and conflict resolution. The results depict that the majority of children ages 3-8 demonstrate the characteristics of social attributes. The data depicts that children ages 3-8 were developed in aspects of social skills attributes: interacting non-verbally, taking part in games, exchanging information with others, participating in group activities, drawing appropriate attention to themselves, attending to short stories, interacting in a socially approved way with adults, responding verbally to social small tasks imitated by adults, exhibiting positive interaction in a group setting, organizing a group to participate in games/activities, and using others in the group to facilitate problem-solving in conflict situations. This development is supported by (Dunn,1995; Hartup, 1992; Child Trends and Center for Child Health Research, 2004; Maynard and Thomas, 2004).

The majority of children ages 3-4 follow peers' requests, play with peers, but feel embarrassed if their habits or words are told to others. The majority of children ages 4-6 initiate a friendly relationship with peers, help and play with them, and greet adults. Similarly, the majority of children show clear attachment, are usually sensitive to peers, and have a preference for friends. The results highlight that the majority of children ages 3-8 exhibit characteristics of peer relationship attributes. The data show that children ages 3-8 were developed in all respects of peer relationship attributes: follow peers' requests, play with peers with a minimal amount of conflict, and feel embarrassed if his words or habits are told to someone, initiate friendly relationships with peers, greet familiar adults/peers without a reminder, help peers with simple tasks, and participate in cooperative play with a small group of children, show a preference for some friends over others, are sensitive to other children/peers, and show clear attachment to peers. A similar pattern of development has been given by Dunn (2004) and Jordan, Carlile and Stack (2008).

The majority of children ages 3-4 understand simple questions, pick up words of older people, imitate, and talk. The majority of children ages 4-6 tell their simple experiences, deliver verbal messages, and describe book 
activities, but hesitate to answer the questions of others. The majority of children ages 6-8 name animals, show interest in novel words, and like to do their work. The results explain that the majority of children ages 3-8 display communication skills attributes.

The data reveals that children ages 3-8 were developed in communication skills: imitate babbling sounds and/or familiar words, understand simple questions, show positive response to talk and pick up words of older people, tell a simple experience, describe items and/or actions in books, believe one part of a verbal message, hesitate to answer the questions of others, name at least eight animals, show an interest in novel words, and like to complete everything themselves. The same pattern of the development of children in childhood has been described by Ladd (2000).

In the above situation, the following questions arise: 1) What are the reasons that the majority of children ages 3-8 in Pakistan are able to demonstrate the attributes which are considered essential for social development?, 2) What are the causes for which some children could not develop attributes that are important for social development?, 3) What are the factors for which the majority of students could not perform well in certain attributes of social development, such as a positive mood, hesitate to answer the questions, and feel embarrassed if their habits are told to others?

Experts, while explaining the process of social development, particularly in the early childhood stage, have identified the different factors, such as parents, family, teachers, peers, siblings, friends, and society, that influence social development (Vygotsky, 1978; Erikson, 1968; Hartup, 1992; Dunn, 1995; Chirstine Johnson and Michall Poteat, 2002; Martin, 2005; Bullock, 1989; Jordan, Carlile and Stack, 2008; Way and Hughes, 2008). As already mentioned, at present, the provision of early childhood education in Pakistan is available only in the private sector. Therefore, the children of strong socio-economic backgrounds have access to early childhood education. The children in this study are included from private schools and the majority belong to socially developed families. Most of the parents are educated. School environment is conducive for social development. The majority of peers and friends are supportive. Teachers are also educated and trained. All these factors may be the causes of social development. The result of this study may be generalised carefully because it is conducted in one segment of society.

The main factors that could contribute toward improper social development of the children in Pakistan are: feudal family background, uneducated parents - particularly mothers, and peers and friends from parents who are uneducated but have a strong economic background.

The factors that can create hurdles in the development of a positive mood are overemphasis on discipline which contributes toward less loving behaviours from others (family, parents - particularly fathers - and sometimes teachers) or more loving behaviours from family, particularly parents. The other factor that could be the cause of being hesitant and feeling embarrassed is the general shyness behaviour of Asian families, parents, society and individuals at large.

\section{CONCLUSION}

The individual attributes that were developed in children ages 3-8 were: fostering a relationship, becoming a group member, school acceptance, humour, and expressing his position in a conflict situation. Sixty to seventy percent of children do not develop a positive attitude due to poor parenting and teaching since children develop their attitudes by learning from their parents and teachers; but on the other hand, the parents in Pakistan do most of the religious and moral training in their child's early years, which lays the foundation for the behaviour. Actually, due to financial and social pressures, parents do not always behave in a positive way in their mutual relationship. If parents are properly trained, they may help their children adopt a positive mood. The parents may be trained through a local Payer Leader who plays a prominent role in Pakistani society. On the other hand, the negative behaviour may be due to poor teaching, which may be due to poor teacher-training, which is almost missing in Pakistan at the early childhood level. This problem is coupled with no service structure and nominal training facilities in early childhood education. The problem can be solved by separating the cadre of Early Childhood Teachers (ECT) and recruiting them as per the needs of every school. Due to limited availability of early childhood teachers, it is suggested that untrained teachers might be recruited and trained later on. 
The social skills, peer relationship, and communication skills attributes were developed in children ages 3-8 of Lahore, Pakistan. This study identified the social development attributes in early childhood in Lahore, Pakistan, and revealed that individual, social skills, peer relationship, and communication skills were developed in children ages 3-8, except a positive mood in children ages 3-4. This may be due to parents' family and social influence on them.

\section{AUTHORS INFORMATION}

Asif, Malik is working as professor in the Department of Education, the University of Sargodha. He has published more than 32 articles in journals of national repute. He did his Ph.D. at the University of Punjab.

Sarwar, Muhammad is presently working as post-doctoral fellow in the Institute of Education, University of Worcester, UK and is Assistant Professor in the Department of Education, University of Sargodha, Pakistan. He did his M.Phil. in Education at Allama Iqbal Open University, Pakistan, and Ph.D. in Education at University Institute of Education and Research, UAAR, Pakistan. E-mail: drsarwar@ymail.com

Khan, Naeemullah is working as Senior Headmaster in the Department of Education, Punjab, Pakistan. He did his Ph.D. in Education at University Institute of Education and Research, UAAR, Pakistan.

\section{REFERENCES}

1. Anne Jordan, orison Carlile, Annetta Stack. (2008). Approaches To Learning. London: Open University Press

2. $\quad$ Blatchford, P. (1998). Social Life in schools. London: The Falmer Press.

3. Bullock, J. R. (1989). The Relationship between Parental Management of Peer Interactions and Children's Social Competence. Family and Consumer Sciences Research Journal, 17 (3), P-263-269.

4. $\quad$ Cardwell, M \& Flnagan, C. (2005). Psychology As: The Complete Companion (revised edition). London: Nelson Thornes.

5. Child Trends and Center for Child Health Research, 2. (2004). Early Child Development in Social Context: A Chartbook. New York: The Common Wealth Fund.

6. Christine Johnson, Marsha Ironsmith, Charles W. Snow1, and G. Michael Poteat (2000). Peer Acceptance and Social Adjustment in Preschool and Kindergarten. Early Childhood Education Journal. Vol. 27, No. 4, 2000, 207-212.

7. Day, J. (1996). School Friendship Groups and their Impact on Learning. Education, 51-58.

8. Donnell, G. (2002) Mastering Sociology, (4th ed.). New York: Palgrave.

9. Dunn, G. (2004). Children's Friendships: Beginning of Intimacy. Oxford: Blackwell.

10. Dunn, J. (1995). Young Children's close relationships. London: Sage Publications.

11. Dunn, J. (2004). Children's Friendships. Oxford: Blackwell Publishing.

12. Erikson, E. H. (1968). Erikson's Stages of Development. Retrieved July 12, 2009, from Learning Theories.com: http://www.learning-theories.com/eriksons-stages-of-development.html

13. Gordon, A. M. and Browne, K. W. (2000). Beginning and Beyond, (5th ed.). New York: Delmar Thomson Learning Inc.

14. Hartup, W. W. (1992). Having Friends, Making Friends, and Keeping Friends: Relationships as Educational Contexts. Urbana, IL: ERIC Clearinghouse on Elementary and Early Childhood Education. ED 345854.

15. Hayes, N. (2002.) Psychology in Perspective. New York: Palgrave.

16. Ladd, L. D. (2000). What Fathers Contribute to Child Development. Texas: The Texas A\&M University System.

17. Li-Jun Ji, Kaiping Peng, Richard E. Nisbett. (2000). Culture, control, and Perceptio of Relationships in the Environment. Journal of Personalty and Social Psychology, 78 (5), 943-955.

18. Martin, E. (2005). Emotional Development and Learning. Early Education, 11-13.

19. Michael J. Guralnick, J., Connor, T. R., Neville, B. and Hammond, A. M. (2006). Promoting the PeerRelated Social Development of Young Children with Mild Developmental Delays: Effectiveness of a Comprehensive Intervention. American Journal on Mental Retardation, 111(5), p. 336-356. 
20. Normar and Seymour (2003). Parental and Home Influences on the Development of aggression in Children, Retrieved from www.marxists.org/html on 7th December, 2003.

21. Park, K. A. Waters, E. (1989). Securrity of Attachment ans Preschool Friendship. Child Development, 1076-1081.

22. Philip G. Erwin, John Letchford. (2003). Types of preschool experience and sociometric status in the primary school. Social behaviour and Personality, 129-132.

23. Piaget's Stages of Cognitive Development. (2009, April 21). Retrieved July 12, 2009, from Psychology.about.com: http://psychology.about.com/b/2008/04/21/key-concepts-in-cognitivedevelopment.htm

24. Rose, Drury. Linda, Miller.Robin, Cambell. (2000). Looking at early years education and care. London: David Fulton Publishers.

25. Tamis-LeMonda, C. S., Way, N., Hughes, D., et al. (2008). Parents' Goals for Children: The Dynamic Coexistence of Individualism and Collectivism in Cultures and Individuals. Dynamics of Collectivism and Individualism, 17 (1), p. 183-209

26. The Science of Early Childhood Development (2007). National Science Counsil on developing child.retrieved on july 5, 2009 from www.developingchild.net

27. The Science of Early Childhood Development. (2007). Harvard: Harvard University.

28. Trisha, Maynard. Negel Thomas. (2004). An Introduction to Early Childhood. London: SAGE Publications.

29. Vygotsky, L. (1978). Vygotsky’s Social Development Theory. Retrieved July 12, 2009, from www.learningtheories.com: http://www.learning-theories.com/vygotskys-social-learning-theory.html 